\title{
Clinical outcomes with a new design in multifocal intraocular lens: a pilot study
}

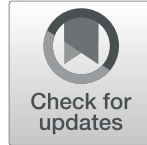

Jorge L. Alió ${ }^{12^{*}}$ (D), Pilar Yébana ${ }^{1}$, Mario Cantó ${ }^{1}$, Ana B. Plaza', Alfredo Vega', Jorge L. Alió del Barrio ${ }^{1,2}$ and

Francisco Lugo'

\begin{abstract}
Purpose: To evaluate the clinical and visual outcomes, quality of near vision and the influence of photic phenomena in patients bilaterally implanted with a new Precizon Presbyopic multifocal intraocular lens (IOL).

Methods: In this prospective consecutive case series, 20 eyes of 10 patients were included (mean age $63.80 \pm$ 12.55 years). Uncorrected and corrected visual acuity (far, intermediate and near), subjective refraction, binocular defocus curve, contrast sensitivity (CSV-1000) and quality of vision and satisfaction questionnaires were measured. The follow-up was 12 months after surgery.

Results: At 12 months after surgery, uncorrected distance visual acuity (UDVA) improved with surgery ( $p=0.001)$ with a value of $0.08 \pm 0.08$ logMAR. Uncorrected near visual acuity (UNVA) was $0.22 \pm 0.12 \log$ MAR and distance corrected near visual acuity (DCNVA) was $0.16 \pm 0.13$ logMAR. Intermediate distance visual acuity (UIVA) was $0.22 \pm$ $0.10 \log$ MAR. Contrast sensitivity outcomes were similar to normal population in photopic conditions and slightly reduced in mesopic conditions of lighting. Defocus curve showed that this multifocal IOL was able to provide a visual acuity (VA) equal or better to 0.16 logMAR between defocus levels of +1.00 to $-2.50 \mathrm{D}$. Good patient satisfaction was obtained in quality of vision and satisfaction questionnaires outcomes.

Conclusions: The Precizon Presbyopic NVA IOL (OPHTEC BV) provides good visual outcomes. This multifocal IOL provides a high percentage of spectacle independence due to good VA at far, intermediate and near distances and satisfactory contrast sensitivity. High patient satisfaction was observed in quality of vision and satisfaction questionnaires with a low percentage of patients manifesting photic phenomena.
\end{abstract}

Keywords: Multifocal intraocular lens, Near vision, Photic phenomena, Continuous transitional focus optic

\section{Introduction}

Nowadays, the demand for multifocal intraocular lenses (IOLs) has increased which can be attributed to the increase of younger patients that demand a solution for their presbyopia and look for spectacle independence. There are a lot of IOLs and designs to provide an excellent visual performance on various distances of sight. These IOLs look for satisfactory visual acuity (VA) and a

\footnotetext{
* Correspondence: jlalio@vissum.com

'Vissum Corporation, Avda de Denia s/n, Edificio Vissum, 03016 Alicante, Spain

2Division of Ophthalmology, Universidad Miguel Hernández, Alicante, Spain
}

suited quality of vision for near, intermediate and far vision [1-4].

The innovation of this Precizon Presbyopic NVA (OPHTEC BV) multifocal intraocular lens (IOL) lies in its new design, an aspherical segmented refractive optic, which conforms a continuous transitional focus (CTF) optic (Fig. 1). This is an optic with an anterior surface with multiple segments for far and near. A smooth transition from far to near is achieved between the segment. This transition offers a constant defocus between the two sharp focal points, delivering a good intermediate vision. Due to the design, patients benefit from good 


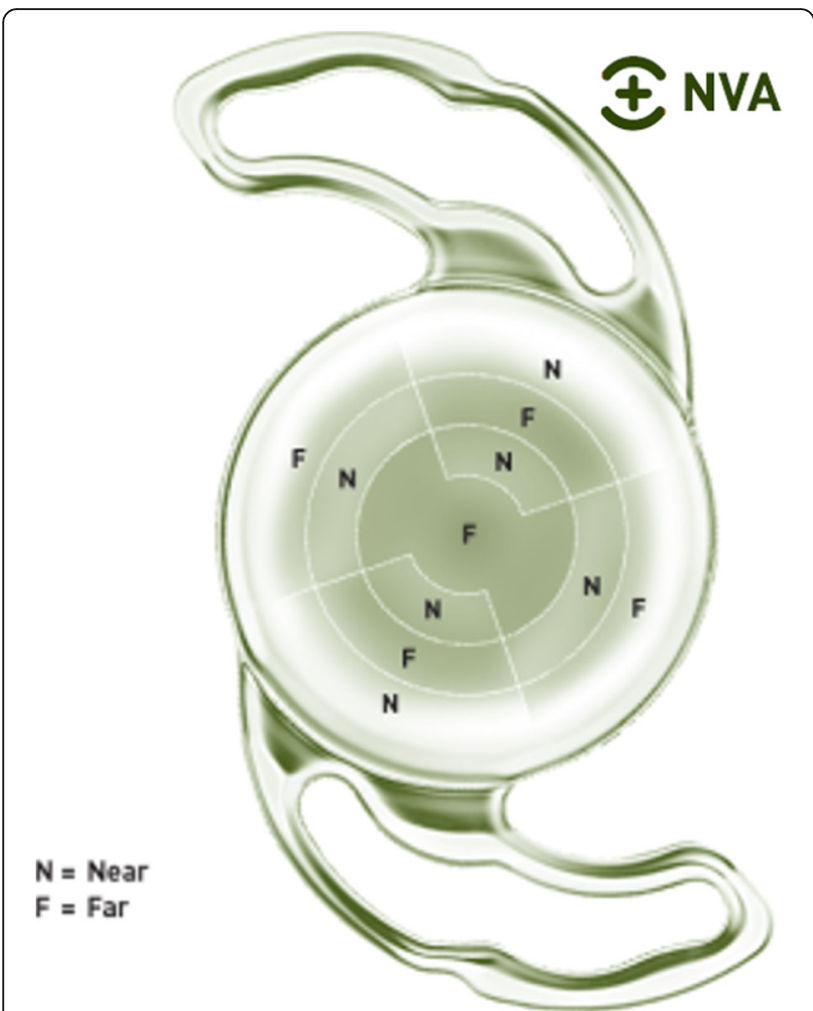

Fig. 1 Precizon Presbyopic multifocal IOL. Design pupil-independent aspherical segmented refractive optic

vision at difference distances independently from the size of the pupil diameter. The use of segments instead of concentric rings should provide better optical quality and reduce photic phenomena.

The aim of this study is to evaluate visual outcomes, quality of near vision and the influence of light distortion in patient bilaterally implanted with this multifocal Precizon Presbyopic IOL.

\section{Methods}

\section{Study design}

This is a monocentric clinical interim pilot study reporting data at 12 months, from one investigation site. This study is a pilot prospective consecutive non-comparative case series.

\section{Patients}

Twenty eyes of 10 patients were bilaterally implanted with the Precizon Presbyopic multifocal IOL. Mean age of the patients was $63.80 \pm 12.55$ years (range: 42 to 79 years). All patients agreed to participate and signed an informed consent. The study adhered to the tenets of the Declaration of Helsinki and was approved by the local ethical committee (Ethics Committee for Drug Research of Cádiz approved this study as an audit study and gave it the following reference number AP01000740).

\section{Intraocular Lens}

The Precizon Presbyopic IOL NVA model 570 (OPTHEC BV) is a one-piece IOL made of a hybrid material hydrophilic/hydrophobic acrylic material with ultraviolet filtering HEMA/EOEMA copolymer, with a refractive index of 1.46. The size of the clear optic diameter is $4.4 \mathrm{~mm}$, with an overall diameter of $12.5 \mathrm{~mm}$.

A multi-zonal design allows the lens to maintain the light distribution and exposure on the foci theoretically regardless of the tilt or decentering of the lens. This IOL provides the ability for a transition in focus between 11 distinct segments (five for distance and six for near vision) with the central segment dedicated for distance vision (Fig. 1). The rotated segments have a width of 0.75 $\mathrm{mm}$ and these segments are distributed in such a way that decentration or pupil size has a minimal effect on the ratio between near and far correction [5].

The IOL optic is designated as CTF and is divided into three concentric sectors: the central sector, of higher diameter, is dedicated to distance correction; two peripheral sectors present a bimodal (50-50\%) distribution of distance and near correction, and this distribution changes along four segments in each sector. This new optic design with an anterior surface with multiple segments for far and near achieves a soft transition from far to near focus. This transition theoretically offers a constant progressive focus between the two sharp focal points to facilitate a sharp image on the retina delivering a good intermediate vision (Fig. 2) [6].

This IOL has a range optic power between +1.0 and $+35.0 \mathrm{D}$ (0.5 D increments) and has an addition of + $2.75 \mathrm{D}$ for near focus.

\section{Inclusion and exclusion criteria}

The inclusion criteria of this study were candidates with early cataract and presbyopia looking for spectacle independence (cataract or clear lens extraction patients) who qualify for bilateral implantation and patients wishing to be spectacle independent. Exclusion criteria were the presence of any other ocular pathology which could compromise visual outcomes (amblyopia, anterior segment comorbidities, glaucoma, retinal disorders or neuro-ophthalmic disease) and preoperative astigmatism higher than 1.0 D measured with optical biometer or corneal topography.

\section{Preoperative and postoperative examination}

All patients were evaluated preoperatively and for each operated eye at day 1 , week 1 and months 1,3 and 12 after surgery. 


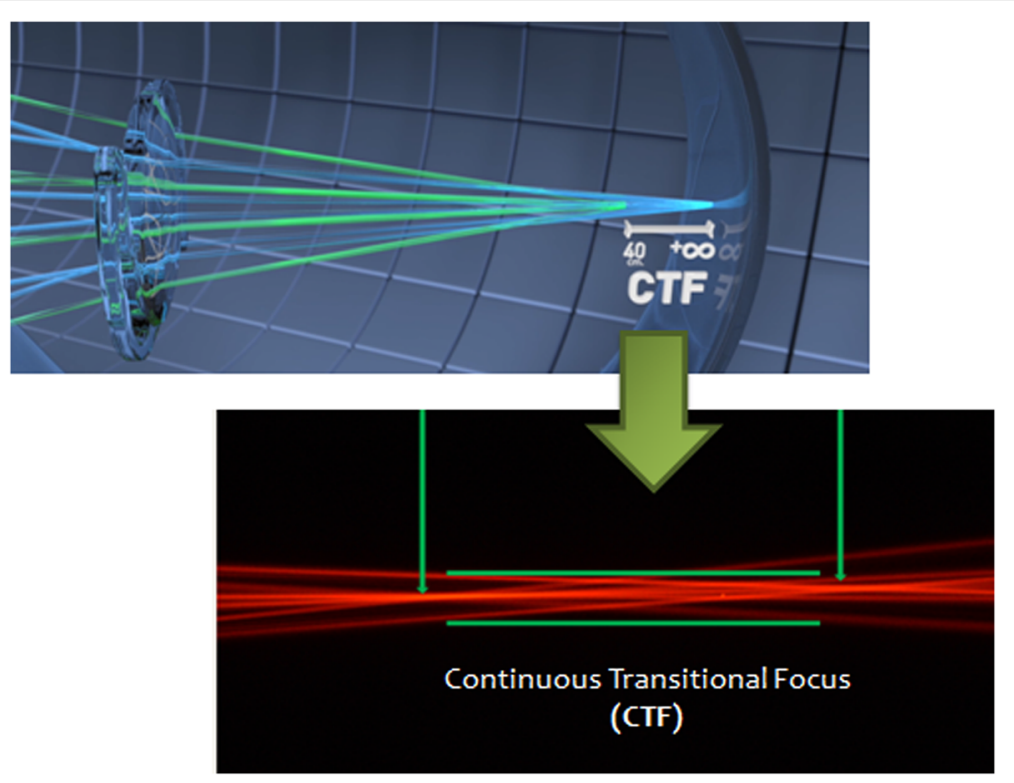

Fig. 2 Continuous Transitional Focus (CTF) optic offers a constant defocus between the two sharp focal points

All measurements were performed by two independent optometrists certified in Good Clinical Practice (ABP and PY) following the same investigational protocol according standard procedures.

The preoperative examination contained an extensive evaluation including: distance visual acuity (DVA) at $4 \mathrm{~m}$ with early treatment diabetic retinopathy study (ETDRS) logMAR charts, subjective refraction, contrast sensitivity in photopic and mesopic conditions with and without glare in binocular vision (CSV-1000, Vector Vision), biometry (IOL Master, Zeiss), pupillometry (Sirius, Costruzione Strumenti Oftalmici), slit-lamp examination, topography (Sirius, Costruzione Strumenti Oftalmici) and quality of vision questionnaire.

Postoperatively, patients were evaluated during the follow-up at 1 day, 1 month, 3 months and 12 months after surgery according the same protocol which included: DVA (ETDRS at $4 \mathrm{~m}$ ), near visual acuity (NVA) (ETDRS reading chart calibrated at $40 \mathrm{~cm}$ ), intermediate visual acuity (IVA) (ETDRS reading chart calibrated at $80 \mathrm{~cm}$ ), subjective refraction, contrast sensitivity (in the same conditions to preoperative evaluation), defocus curve in binocular vision, slit-lamp examination, quality of vision [7] and satisfaction questionnaire (a questionnaire adapted for this study was used).

Defocus curve was performed in binocular conditions with the postoperative manifest refraction corrected following the protocol previously published [8-10]. The defocus curve was obtained using ETDRS charts at $4 \mathrm{~m}$. Negative lenses were added in $0.50 \mathrm{D}$ steps and the VA was recorded for each type of defocus level. Afterwards, the same procedure was repeated using positive lenses.
The range of defocus curve evaluated was from -5.00 to $+1.50 \mathrm{D}$. In the defocus curve, $0.00 \mathrm{D}$ of defocus corresponds to far vision, $-1.50 \mathrm{D}$ of defocus corresponds to intermediate vision and $-2.50 \mathrm{D}$ of defocus to near vision.

Contrast sensitivity vision was performed in binocular conditions at a distance of $2.5 \mathrm{~m}$ for 4 frequencies in cycles per degree (cpd) (A: $3 \mathrm{cpd}, \mathrm{B}: 6 \mathrm{cpd}, \mathrm{C}: 12 \mathrm{cpd}$ and D: $18 \mathrm{cpd}$ ) and patients were tested with the postoperative manifest refraction corrected. Four measurements have been performed for each patient, in photopic and mesopic conditions with and without glare. To measure contrast sensitivity in mesopic light condition we used specially designed mesopic (neutral density) filters to reduce the testing light level. The CSV-1000 test provides a glare option, this test incorporates a standardized halogen glare test so it can be used under glare conditions.

\section{Statistical analysis}

The statistical analysis was performed with the SPSS software for Windows (IBM SPSS Statistics, version $22.0)$. Due to small sample size $(n<30)$, our variables were considered non-normal, and thus we used nonparametric tests for data analysis.

For the continuous variables observed, the Wilcoxon test was used to assess the difference between preoperative and postoperative outcomes. Differences were considered statistically significant when the $P$ value was less than 0.05 .

\section{Results}

A total of 20 eyes of 10 patients (70\% cataract; $30 \%$ clear lens extraction) were examined 12 months postoperatively. 


\section{Visual acuity and refractive status}

Table 1 shows the monocular postoperative refraction and VA in $\operatorname{logMAR}$ results 3 and 12 months postoperatively. Uncorrected distance visual acuity (UDVA) improved with the surgery at 3 and 12 months $(p<0.001)$, it even had a significant improvement between the third and twelfth month $(p=0.015)$. Corrected distance visual acuity (CDVA) improved significantly after surgery $(p<$ $0.05)$ and remained stable over time $(p=0.074)$. The outcomes at 12 months of uncorrected near visual acuity (UNVA) at $40 \mathrm{~cm}$ and distance corrected near visual acuity (DCNVA) at $4 \mathrm{~m}$ was $0.22 \pm 0.12 \log$ MAR and $0.16 \pm 0.13 \log$ MAR respectively, remaining stable over time between postoperative visits $(p>0.05)$. At 3 months, corrected near visual acuity (CNVA) was $0.08 \pm$ $0.05 \operatorname{logMAR}$, and for intermediate vision the results showed an uncorrected intermediate visual acuity (UIVA) of $0.22 \pm 0.10 \log$ MAR.

Table 2 shows the binocular VA and refractive results at 3 and 12 months after surgery. Binocularly, the outcomes of this IOL shows an improvement in UDVA after surgery at 3 and 12 months $(p<0.05)$, they even had a significant improvement between the third and twelfth month $(p=0.040)$. The uncorrected visual acuity outcomes of distance and near at 12 months after surgery were $-0.01 \pm 0.05 \log$ MAR and $0.13 \pm 0.12 \log M A R$, respectively. Intermediate vision at 3 months was $0.16 \pm$ $0.11 \log$ MAR.

Figure 3 shows the distribution of the postoperative spherical equivalent for all eyes at 12 months, $65 \%$ of eyes obtained a spherical equivalent between $\pm 0.50 \mathrm{D}$ and $90 \%$ of eyes between $\pm 1.00 \mathrm{D}$.

\section{Defocus curve}

The binocular defocus curve is shown in Fig. 4. At 12 months, the maximum value of VA obtained was -0.08 $\pm 0.08 \log$ MAR corresponding to the far defocus $(0.00 \mathrm{D})$. A second peak was found at $-2.00 \mathrm{D}$ with a VA of $0.08 \pm 0.12 \operatorname{logMAR}$. Corresponding to near defocus $(-2.50 \mathrm{D})$ the VA obtained was $0.16 \pm 0.15 \log$ MAR while for intermediate vision $(-1.50 \mathrm{D})$ the VA was $0.12 \pm 0.11 \log$ MAR. As shown, this multifocal IOL was able to provide a VA equal or better to 0.16 LogMAR between defocus levels of +1.00 to $-2.50 \mathrm{D}$.

\section{Contrast sensitivity}

The outcomes of contrast sensitivity in photopic and mesopic conditions and measurement with and without glare in binocular vision at 3 months are shown in Fig. 5 . This multifocal IOL provides contrast sensitivity values (in log units) similar to those observed in normal population, for an age group between 50 and 75 years of age (Table 3), in photopic lighting conditions (A: 1.68, B: 1.74, C: 1.53 , D: 1.05) and slightly reduced in mesopic lighting conditions (A: 1.59, B: 1.68, C: 1.28, D: 0.78).

\section{Questionnaires \\ Quality of vision questionnaire}

Table 4 shows the subjective quality of vision reported by patients at 3 and 12 months postoperatively. At 12 months, $70 \%$ of patients reported that they "never" observed glare and $30 \%$ of patients said that they had seen glares "occasionally". With respect to halos, $40 \%$ of patients reported that they "never" observed halos, $40 \%$ "occasionally", $20 \%$ of patients reported that they "often" seen halos, and $0 \%$ of patients reported "usually" seeing halos.

\section{Satisfaction questionnaire}

Table 5 shows the subjective satisfaction reported by patients at 12 months postoperatively. The satisfaction questionnaire shows that overall, $90 \%$ of patients were

Table 1 Postoperative monocular refractive results and visual acuities at 3 and 12 months

\begin{tabular}{|c|c|c|c|c|c|c|}
\hline & $\begin{array}{l}\text { Preoperative } \\
\text { Visit }\end{array}$ & $\begin{array}{l}\text { Postoperative } \\
\text { Visit } 3 \text { Months }\end{array}$ & $\begin{array}{l}\text { Postoperative } \\
\text { Visit } 12 \text { Months }\end{array}$ & $p$-value & $p$-value & $p$-value \\
\hline Refractive status & Mean \pm SD & Mean \pm SD & Mean \pm SD & Pre-3 M & Pre-12M & $3 \mathrm{M}-12 \mathrm{M}$ \\
\hline Sphere (D) & $0.77 \pm 1.87$ & $0.58 \pm 0.41$ & $0.62 \pm 0.48$ & 0.641 & 0.675 & 0.762 \\
\hline Cylinder (D) & $-0.67 \pm 0.69$ & $-0.46 \pm 0.42$ & $-0.49 \pm 0.39$ & 0.209 & 0.256 & 0.832 \\
\hline SE (D) & $0.43 \pm 2.05$ & $0.36 \pm 0.42$ & $0.38 \pm 0.48$ & 0.857 & 0.888 & 0.838 \\
\hline \multicolumn{7}{|c|}{ Visual Acuity (logMAR) } \\
\hline UDVA & $0.51 \pm 0.30$ & $0.13 \pm 0.09$ & $0.08 \pm 0.08$ & $<0.001^{*}$ & $<0.001^{*}$ & $0.015^{*}$ \\
\hline CDVA & $0.13 \pm 0.22$ & $0.02 \pm 0.06$ & $-0.01 \pm 0.05$ & $0.033^{*}$ & $0.012^{*}$ & 0.074 \\
\hline UNVA & - & $0.22 \pm 0.11$ & $0.22 \pm 0.12$ & - & - & 0.868 \\
\hline DCNVA & - & $0.18 \pm 0.10$ & $0.16 \pm 0.13$ & - & - & 0.242 \\
\hline CNVA & - & $0.08 \pm 0.05$ & - & - & - & - \\
\hline UIVA & - & $0.22 \pm 0.10$ & - & - & - & - \\
\hline
\end{tabular}

$S E=$ Spherical equivalent, $D=$ Diopters, $M=$ Months, UDVA= Uncorrected distance visual acuity, $C D V A=$ Corrected distance visual acuity, UNVA= Uncorrected near visual acuity, DCNVA= Distance corrected near visual acuity, CNVA= Corrected near visual acuity, UIVA= Uncorrected intermediate visual acuity 
Table 2 Postoperative binocular visual acuities at 3 and 12 months

\begin{tabular}{|c|c|c|c|c|c|c|}
\hline & $\begin{array}{l}\text { Preoperative } \\
\text { Visit }\end{array}$ & $\begin{array}{l}\text { Postoperative } \\
\text { Visit } 3 \text { Months }\end{array}$ & $\begin{array}{l}\text { Postoperative } \\
\text { Visit } 12 \text { Months }\end{array}$ & $p$-value & $p$-value & $p$-value \\
\hline Visual Acuity (logMAR) & Mean \pm SD & Mean \pm SD & Mean \pm SD & Pre-3 M & Pre-12M & $3 \mathrm{M}-12 \mathrm{M}$ \\
\hline UDVA & $0.34 \pm 0.26$ & $0.04 \pm 0.04$ & $-0.01 \pm 0.05$ & $0.007^{*}$ & $0.002^{*}$ & $0.040^{*}$ \\
\hline CDVA & $0.01 \pm 0.15$ & $-0.03 \pm 0.04$ & $-0.11 \pm 0.13$ & 0.510 & 0.057 & 0.081 \\
\hline UNVA & - & $0.15 \pm 0.13$ & $0.13 \pm 0.12$ & - & - & 0.500 \\
\hline DCNVA & - & $0.15 \pm 0.14$ & $0.08 \pm 0.11$ & - & - & 0.064 \\
\hline CNVA & - & $0.08 \pm 0.05$ & - & - & - & - \\
\hline UIVA & - & $0.16 \pm 0.11$ & - & - & - & - \\
\hline
\end{tabular}

$U D V A=$ Uncorrected distance visual acuity, $C D V A=$ Corrected distance visual acuity, $U N V A=$ Uncorrected near visual acuity, $D C N V A=$ Distance corrected near visual acuity, $C N V A=$ Corrected near visual acuity, UIVA= Uncorrected intermediate visual acuity, $M=$ Months

satisfied with their visual results: $80 \%$ of patients were very satisfied, $10 \%$ of patients were quite satisfied with the surgery, and $10 \%$ of patients were dissatisfied with their visual outcomes.

Sixty percent of patients answered that they had not required the use of glasses after surgery, $20 \%$ had used spectacles for near vision "occasionally" and the other $20 \%$ had "often" used spectacles for near vision.

\section{Discussion}

Multifocal IOLs aim to provide a good distance, intermediate and near visual outcomes because more often, daily activities requires a high range of vision (for example, use of computers, tablets or car dashboard) $[1,2]$.

In agreement with previous studies with multifocal IOLs (better than $0.10 \operatorname{logMAR}$ ) [1], this IOL provides a good VA $(0.08 \pm 0.08$ logMAR $)$ for distance vision [2, 11-30]. Near vision outcomes achieved in this study $(0.22 \pm 0.12 \log \mathrm{MAR})$ were compatible with other publications (better than 0.30 logMAR) with difference models of multifocal IOLs $[1,2,11,13,14,16,17,19-$ $21,24,26-33]$. The intermediate visual outcomes obtained in this study $(0.22 \pm 0.10 \log$ MAR $)$ were similar with other reports (better than $0.30 \log$ MAR) $[1,2,12$, $13,16,17,21,22,24,25,31-33]$.

The outcomes of the defocus curve binocular analysis show that this IOL provides an acceptable VA with a defocus range of +1.00 to $-2.50 \mathrm{D}$ (VA equal or better to 0.16 LogMAR), according to a previous study which defined $0.30 \log M A R$ as the limit of good vision [9]. The outcomes of the defocus curve show good values of VA for far vision defocus $(-0.08 \pm 0.08 \log$ MAR $)$, near defocus $(0.16 \pm 0.15 \operatorname{logMAR})$ and intermediate defocus $(0.12 \pm 0.11 \log$ MAR $)$. Outcomes in binocular defocus curve are similar to other IOLs [10, 34].

In this study, contrast sensitivity was measured with the CSV-1000 test in different conditions of light, photopic and mesopic conditions and with and without glare in binocular vision. Regarding contrast sensitivity

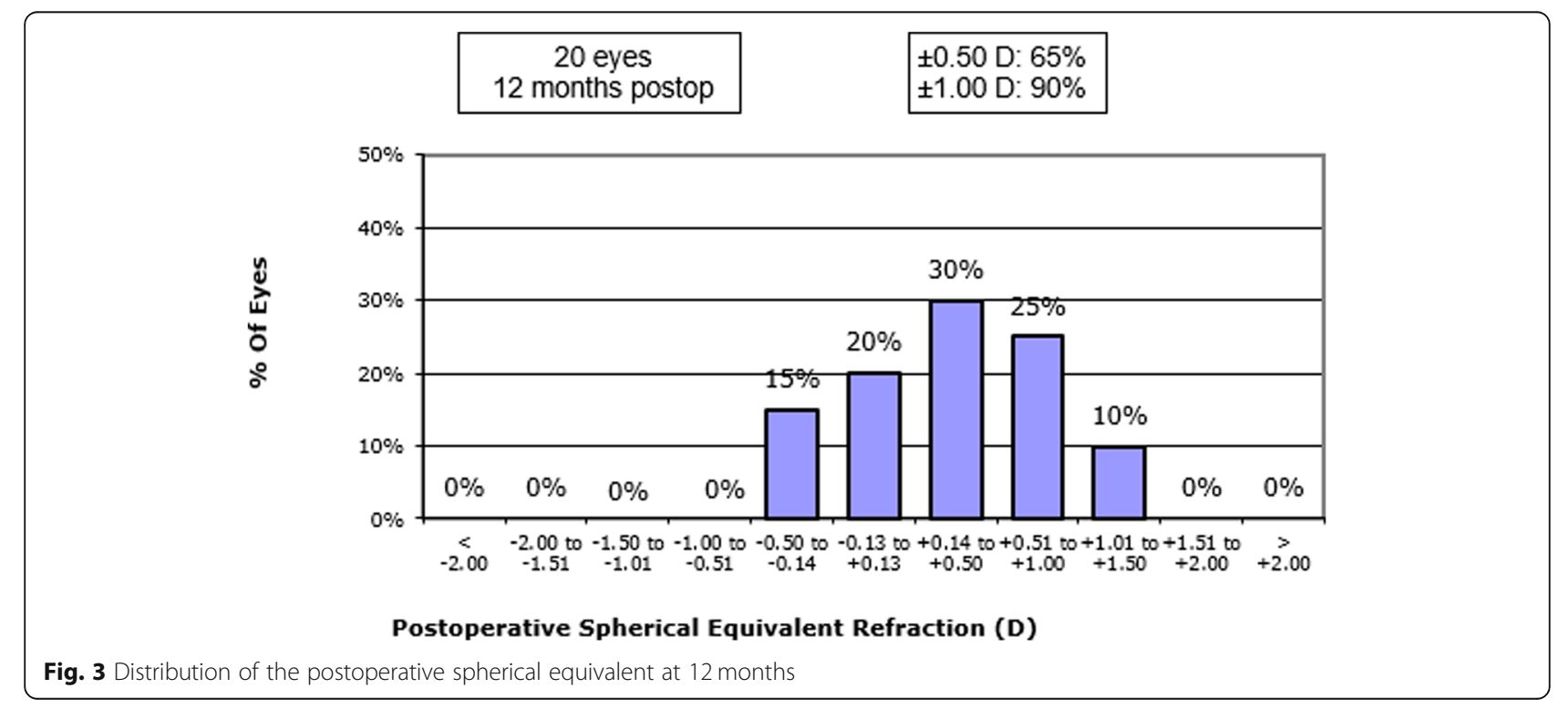




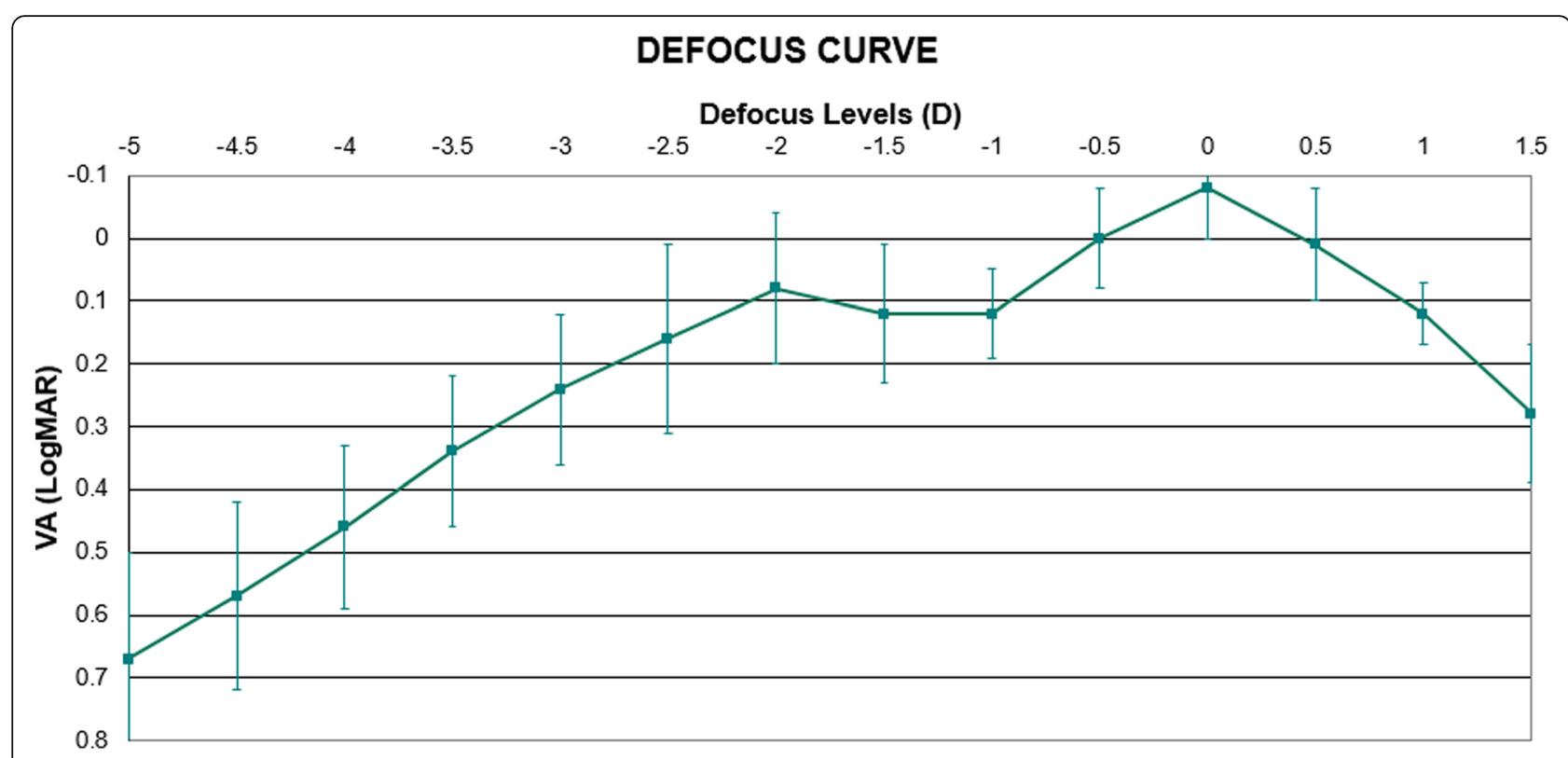

Fig. 4 Binocular defocus curve 12 months postoperatively

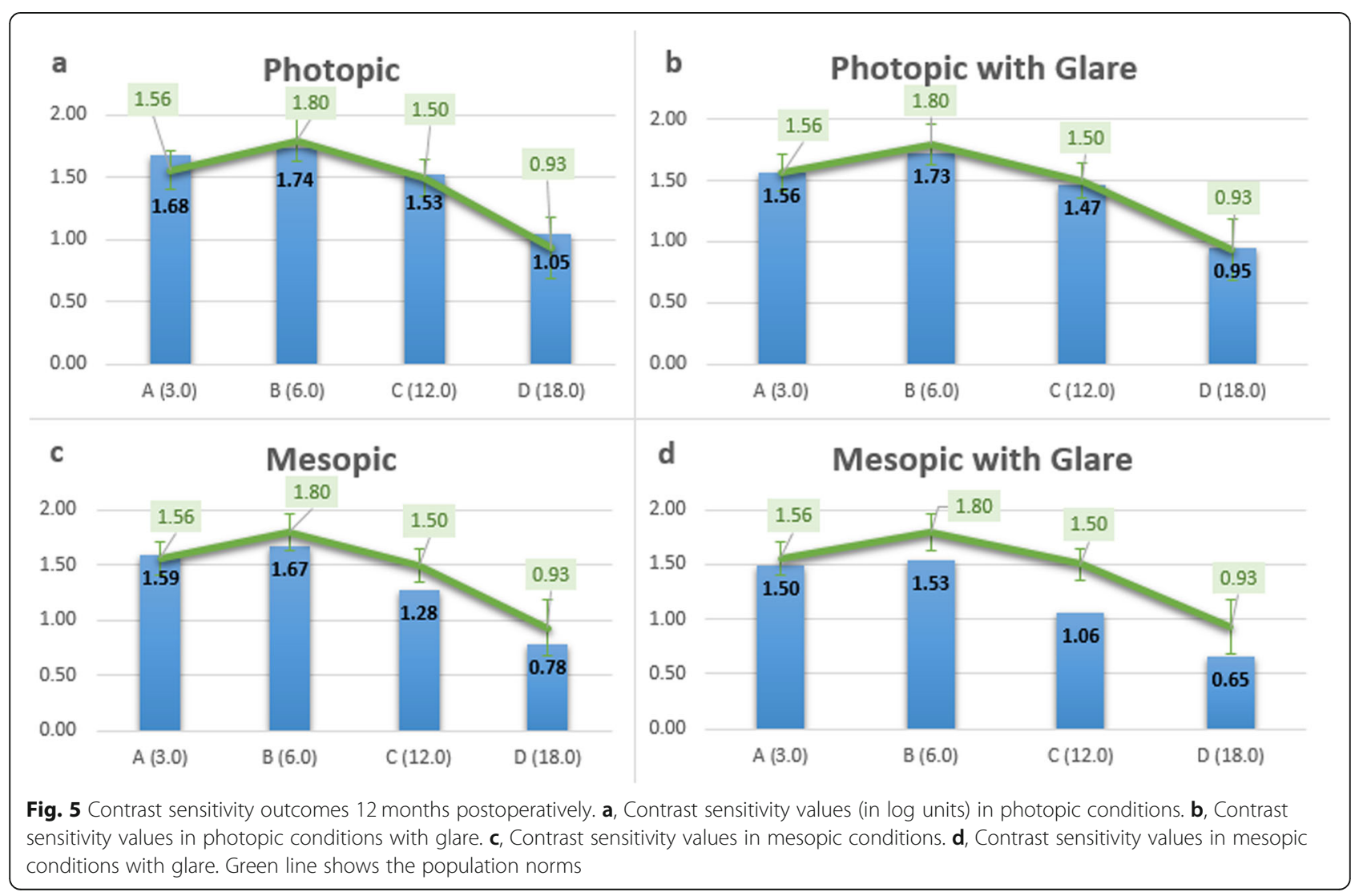


Table 3 Population norms in contrast sensitivity (CSV-1000 test) for an age group between 50 and 75 years of age

\begin{tabular}{lllll}
\hline & $\mathrm{A}(3.0)$ & $\mathrm{B}(6.0)$ & $\mathrm{C}(12.0)$ & $\mathrm{D}(18.0)$ \\
\hline Log Values & 1.56 & 1.80 & 1.50 & 0.93 \\
SD & 0.15 & 0.17 & 0.15 & 0.25 \\
\hline
\end{tabular}

outcomes, this multifocal IOL provides contrast sensitivity values similar to the normal population, for an age group between 50 and 75 years of age, in photopic lighting conditions and slightly reduced in mesopic conditions [35]. Another previous study reported lower contrast sensitivity in multifocal IOLs in mesopic lighting conditions [36].

The subjective quality of vision and patient's satisfaction was evaluated with two questionnaires at 3 and 12 months after surgery. Outcomes in quality of vision questionnaire at 12 months show that a high percentage of patients reported that they had never seen glares (70\%) and $80 \%$ of patients reported that they "never" or only "occasionally" seen halos (40\% "never"; $40 \%$ "occasionally"), and $20 \%$ of patients reported that they had seen halos "often" and $0 \%$ of patients reported "usually" seeing halos.

The satisfaction questionnaire revealed that $90 \%$ of patients were satisfied in general with their visual results and $10 \%$ of patient reported that they were dissatisfied with visual outcomes. Only one patient reported was dissatisfied, the reason was a poor neuroadaptation and discomfort due to perception of photic phenomena, especially at night, and the fact that he was a demanding patient, despite having a good VA and not showing a postoperative refractive defect. $60 \%$ of patients answered that they had not required the use of glasses after surgery, $20 \%$ had used spectacles for near vision "occasionally" to perform near visual activities which require precise details or read small print letters and $20 \%$ of patient had used spectacles for near vision "often".

The main limitation of the current work is its pilot nature, which includes only a several cases [37]. Recently, another study reporting clinical outcomes with this lens has been published [5]. In that study, Royo et al. [5] included both eyes for analysis of VA and refractive parameters. Regarding VA values, results were obtained 6 months after the operation, while in our study results were obtained at 12 months. The monocular and binocular UDVA values were similar (0.03 logMAR and $0.01 \log$ MAR, respectively). The UNVA and UIVA values were slightly higher than those obtained in this study. This may be due to the value of SE mean $(-0.54$ D) being slightly more myopic than our research. These previous results can be reflected by comparing the defocus curve; where it can be observed that our curve is displaced towards the top in far defocus, while we
Table 4 Outcomes of quality of vision questionnaire (3 and 12 months postop)

\begin{tabular}{|c|c|c|c|}
\hline & & $\begin{array}{l}3 \\
\text { months }\end{array}$ & $\begin{array}{l}12 \\
\text { months }\end{array}$ \\
\hline \multirow[t]{4}{*}{ 1. How often do you perceive glares? } & Never & $60 \%$ & $70 \%$ \\
\hline & Occasionally & $20 \%$ & $30 \%$ \\
\hline & Often & $10 \%$ & $0 \%$ \\
\hline & Usually & $10 \%$ & $0 \%$ \\
\hline \multirow[t]{4}{*}{ 2. How often do you see halos? } & Never & $60 \%$ & $40 \%$ \\
\hline & Occasionally & $30 \%$ & $40 \%$ \\
\hline & Often & $0 \%$ & $20 \%$ \\
\hline & Usually & $10 \%$ & $0 \%$ \\
\hline \multirow[t]{4}{*}{ 3. How often do you see flashes? } & Never & $40 \%$ & $50 \%$ \\
\hline & Occasionally & $20 \%$ & $30 \%$ \\
\hline & Often & $0 \%$ & $10 \%$ \\
\hline & Usually & $40 \%$ & $10 \%$ \\
\hline \multirow{4}{*}{$\begin{array}{l}\text { 4. How often do you have the feeling } \\
\text { of looking through dirty glass? }\end{array}$} & Never & $60 \%$ & $90 \%$ \\
\hline & Occasionally & $40 \%$ & $10 \%$ \\
\hline & Often & $0 \%$ & $0 \%$ \\
\hline & Usually & $0 \%$ & $0 \%$ \\
\hline \multirow[t]{4}{*}{ 5. How often do you have blur vision? } & Never & $60 \%$ & $90 \%$ \\
\hline & Occasionally & $40 \%$ & $10 \%$ \\
\hline & Often & $0 \%$ & $0 \%$ \\
\hline & Usually & $0 \%$ & $0 \%$ \\
\hline \multirow{4}{*}{$\begin{array}{l}\text { 6. How often do you have distortion } \\
\text { vision? }\end{array}$} & Never & $70 \%$ & $90 \%$ \\
\hline & Occasionally & $30 \%$ & $10 \%$ \\
\hline & Often & $0 \%$ & $0 \%$ \\
\hline & Usually & $0 \%$ & $0 \%$ \\
\hline \multirow{4}{*}{$\begin{array}{l}\text { 7. How often do you have double } \\
\text { vision? }\end{array}$} & Never & $80 \%$ & $90 \%$ \\
\hline & Occasionally & $20 \%$ & $10 \%$ \\
\hline & Often & $0 \%$ & $0 \%$ \\
\hline & Usually & $0 \%$ & $0 \%$ \\
\hline \multirow{4}{*}{$\begin{array}{l}\text { 8. How often do you have } \\
\text { fluctuations in your vision? }\end{array}$} & Never & $60 \%$ & $70 \%$ \\
\hline & Occasionally & $30 \%$ & $30 \%$ \\
\hline & Often & $10 \%$ & $0 \%$ \\
\hline & Usually & $0 \%$ & $0 \%$ \\
\hline \multirow{4}{*}{$\begin{array}{l}\text { 9. How often do you have difficult to } \\
\text { focus? }\end{array}$} & Never & $40 \%$ & $40 \%$ \\
\hline & Occasionally & $50 \%$ & $50 \%$ \\
\hline & Often & $10 \%$ & $0 \%$ \\
\hline & Usually & $0 \%$ & $10 \%$ \\
\hline \multirow{4}{*}{$\begin{array}{l}\text { 10. How often do you have difficult to } \\
\text { perceive distances or depth? }\end{array}$} & Never & $80 \%$ & $80 \%$ \\
\hline & Occasionally & $20 \%$ & $20 \%$ \\
\hline & Often & $0 \%$ & $0 \%$ \\
\hline & Usually & $0 \%$ & $0 \%$ \\
\hline
\end{tabular}


Table 5 Outcomes of satisfaction questionnaire (12 months postop)
1. How satisfied are you with the overall result of the procedure?
Dissatisfied 10\% A little 0\%
Quite satisfied 10\% Very satisfied $80 \%$

2. How satisfied are you with your uncorrected vision?
No $10 \%$
A little $0 \%$
Considerably $40 \%$
A lot $50 \%$

3. How satisfied are you with your near vision?

No $10 \% \quad$ A little $20 \% \quad$ Considerably $10 \%$ A lot $60 \%$

4. How satisfied are you with your intermediate vision?
No $10 \%$
A little $20 \%$
Considerably $50 \%$
A lot $40 \%$

5. How satisfied are you with your far vision?

No $0 \% \quad$ A little $10 \% \quad$ Considerably $40 \%$ A lot $50 \%$

6. Did you get the visual quality you wanted?

No $10 \% \quad$ Maybe $0 \% \quad$ Considerably $10 \%$ Ýes $80 \%$

7. Has this lens been a good choice?

No $10 \% \quad$ A little $0 \% \quad$ Considerably 0\% A lot 50\%

8. With your current experience, would you operate again?

No $10 \% \quad$ Maybe $0 \% \quad$ Considerably $0 \% \quad$ Ýes $90 \%$

9. Would you recommend the implantation of this lens to another person?

No $10 \% \quad$ Maybe $0 \% \quad$ Considerably 0\% Ýes $90 \%$

10. How often do you still wear your glasses or contact lenses?

$\begin{array}{lll}\text { Never } 60 \% & \text { Occasionally } \\ 20 \% & \text { Often } 20 \% \quad \text { Most often } 0 \%\end{array}$

11. If you wear glasses, for what distance?

$\begin{array}{llll}\text { Not available } & \text { Near vision } & \text { Intermediate vision } & \text { Far vision } 0 \% \\ 60 \% & 40 \% & 0 \% & \end{array}$

intermediate and near distances. Patients obtained good contrast sensitivity. Good patient satisfaction was shown in quality of vision and satisfaction questionnaires with a low percentage of patients manifesting photic phenomena. Future investigations are required to determine the long follow-up outcomes with this new multifocal IOL.

\title{
Acknowledgements
}

Not applicable.

\begin{abstract}
Authors' contributions
$J L$ performed medical operations and medical examinations of patients, written and approved the manuscript. PY performed optometrists examinations, data collection and written the manuscript. $M C$ performed data collection, statistical analysis and written the manuscript. ABP performed optometrists examination and reviewed the manuscript. AV performed medical operations and reviewed the manuscript. JAB medical operations and medical examinations and reviewed the manuscript. FL performed medical operations and reviewed the manuscript. All authors read and approved the final manuscript.
\end{abstract}

\section{Funding}

Network for Cooperative Research in Health "OFTARED" - Reference: RD16/ 0008/0012. Funded by Instituto de Salud Carlos III and co-funded by European Regional Development Fund (ERDF), "A way to make Europe".

\section{Availability of data and materials}

The datasets used and/or analysed during the current study are available from the corresponding author on reasonable request.

\section{Ethics approval and consent to participate}

All patients gave their informed consent for their anonymized data to be submitted for audit and publication. Ethics Committee for Drug Research of Cádiz approved this study as an audit study and gave it the following reference number AP01000740.

\section{Consent for publication}

Not applicable.

\section{Competing interests}

The authors have no proprietary or commercial interest in the medical devices that are involved in this manuscript.

observed similar outcomes for intermediate vision, and our outcomes for near defocus were slightly reduced. In general, their defocus curve outcomes, same as our results, provides an acceptable VA with a defocus range of +1.00 to $-2.50 \mathrm{D}(0.30 \log \mathrm{MAR}$ as the limit of good vision) [9]. Values of contrast sensitivity and photic phenomena were similar. Nevertheless, further studies with larger samples and without this potential bias are required for confirming these outcomes. The difference compared with Royo et al. [5] study, is that they asked verbally about the perception of disturbing photic phenomena while in our study we measured subjectively the perception of photic phenomena through a validated questionnaire [7].

\section{Conclusions}

In conclusion, the Precizon Presbyopic NVA IOL provides good visual outcomes. This multifocal IOL provides a high percentage of spectacle independence after bilateral implantation. Patients reported satisfactory full range of vision with good values of VA at far,

Received: 3 December 2019 Accepted: 27 June 2020

Published online: 18 July 2020

References

1. Alió JL, Plaza-Puche AB, Férnandez-Buenaga R, Pikkel J, Maldonado M. Multifocal intraocular lenses: an overview. Surv Ophthalmol. 2017;62(5):611-34.

2. Alió J, Plaza-Puche AB, Alió Del Barrio JL, Amat-Peral P, Ortuño V, Yébana P, et al. Clinical outcomes with a diffractive trifocal intraocular lens. Eur J Ophthalmol. 2018;28(4):419-24.

3. Breyer DRH, Kaymak H, Ax T, Kretz FTA, Auffarth GU, Hagen PR. Multifocal intraocular lenses and extended depth of focus intraocular lenses. Asia Pac J Ophthalmol (Phila). 2017;6(4):339-49.

4. Kohnen T, Titke C, Bohm M. Trifocal intraocular lens implantation to treat visual demands in various distances following lens removal. Am J Ophthalmol. 2016;161:71-7.e1.

5. Royo MM, Jiménez A, Piñero DP. Clinical outcomes of cataract surgery with implantation of a continuous transitional focus intraocular lens. J Cataract Refract Surg. 2020;46(4):567-72.

6. Mesa RR, Monteiro T. Continuous transitional focus (CTF): a new concept in ophthalmic surgery. Ophthalmol Ther. 2018;7:223-1.

7. McAlinden C, Pesudovs K, Moore JE. The development of an instrument to measure quality of vision: the Quality of Vision (QoV) questionnaire. Invest Ophthalmol Vis Sci. 2010;51(11):5537-45.

8. Vargas V, Radner W, Allan BD, Reinstein DZ, Burkhard Dick H, Alió JL. Methods for the study of near, intermediate vision, and accommodation: an 
overview of subjective and objective approaches. Surv Ophthalmol. 2019; 64(1):90-100.

9. Buckhurst PJ, Wolffsohn JS, Naroo SA, Davies LN, Bhogal GK, Kipioti A, et al. Multifocal intraocular lens differentiation using defocus curves. Invest Ophthalmol Vis Sci. 2012;53(7):3920-6.

10. Plaza-Puche AB, Alió JL. Analysis of defocus curves of different modern multifocal intraocular lenses. Eur J Ophthalmol. 2016;26(5):412-7.

11. Zhao G, Zhang J, Zhou Y, Hu L, Che C, Jiang N. Visual function after monocular implantation of apodized diffractive multifocal or single-piece monofocal intraocular lens randomized prospective comparison. J Cataract Refract Surg. 2010;36(2):282-5.

12. Lane SS, Javitt JC, Nethery DA, Waycaster C. Improvements in patient reported outcomes and visual acuity after bilateral implantation of multifocal intraocular lenses with +3.0 diopter addition: multicenter clinical trial. J Cataract Refract Surg. 2010;36(11):1887-96.

13. Alió JL, Pinero DP, Plaza-Puche A, Amparo F, Jiménez R, Rodríguez-Prats JL, et al. Visual and optical performance with two different diffractive multifocal intraocular lenses compared to a monofocal lens. J Refract Surg. 2011;27(8): 570-81.

14. Muñoz G, Albarrán-Diego C, Cerviño A, Ferrer-Blasco T, García-Lázaro S. Visual and optical performance with the ReZoom multifocal intraocular lens. Eur J Ophthalmol. 2012;22(3):356-62.

15. van der Linden JW, van Velthoven M, van der Meulen I, Nieuwendaal C, Mourits M, Lapid-Gortzak R. Comparison of a new-generation sectorial addition multifocal intraocular lens and a diffractive apodized multifocal intraocular lens. J Cataract Refract Surg. 2012;38(1):68-73.

16. Alió JL, Plaza-Puche AB, Javaloy J, Ayala MJ, Moreno L, Piñero DP. Comparison of a new refractive multifocal intraocular lens with an inferior segmental near add and a diffractive multifocal intraocular lens. Ophthalmology. 2012;119(3):555-63.

17. Sheppard AL, Shah S, Bhatt U, Bhogal G, Wolffsohn JS. Visual outcomes and subjective experience after bilateral implantation of a new diffractive trifocal intraocular lens. J Cataract Refract Surg. 2013;39(3):343-9.

18. van der Linden JW, van der Meulen IJ, Mourits MP, Lapid-Gortzak R. Comparison of a hydrophilic and a hydrophobic apodized diffractive multifocal intraocular lens. Int Ophthalmol. 2013;33(5):493-500.

19. Venter J, Pelouskova M. Outcomes and complications of a multifocal toric intraocular lens with a surface-embedded near section. J Cataract Refract Surg. 2013;39(6):859-66.

20. Venter JA, Pelouskova M, Collins BM, Schallhorn SC, Hannan SJ. Visual outcomes and patient satisfaction in 9366 eyes using a refractive segmented multifocal intraocular lens. J Cataract Refract Surg. 2013;39(10): 1477-84.

21. Rosa AM, Loureiro Silva MF, Lobo C, Mira JB, Farinha CL, Póvoa JA, et al. Comparison of visual function after bilateral implantation of inferior sectorshaped near-addition and diffractive-refractive multifocal IOLs. J Cataract Refract Surg. 2013:39(11):1653-9.

22. Alfonso JF, Knorz M, Fernández-Vega L, Rincón JL, Suarez E, Titke C, et al. Clinical outcomes after bilateral implantation of an apodized +3.0 D toric diffractive multifocal intraocular lens. J Cataract Refract Surg. 2014:40(1):51-9.

23. Cochener B, Vryghem J, Rozot P, Lesieur G, Chevalier JP, Henry JM, et al. Clinical outcomes with a trifocal intraocular lens: a multicenter study. J Refract Surg. 2014;30(11):762-8.

24. Kim JS, Jung JW, Lee JM, Seo KY, Kim EK, Kim TI. Clinical outcomes following implantation of diffractive multifocal intraocular lenses with varying add powers. Am J Ophthalmol. 2015;160(4):702-9.e1.

25. Kretz FT, Bastelica A, Carreras H, Ferreira T, Müller M, Gerl M, et al. Clinical outcomes and surgeon assessment after implantation of a new diffractive multifocal toric intraocular lens. Br J Ophthalmol. 2015;99(3):405-11.

26. Alió JL, Elkady B, Ortiz D, Bernabeu G. Clinical outcomes and intraocular optical quality of a diffractive multifocal intraocular lens with asymmetrical light distribution. J Cataract Refract Surg. 2008;34(6):942-8.

27. Alió JL, Piñero DP, Plaza-Puche AB, Chan MJ. Visual outcomes and optical performance of a monofocal intraocular lens and a new-generation multifocal intraocular lens. J Cataract Refract Surg. 2011;37(2):241-50.

28. Alió JL, Pinero DP, Tomas J, Plaza AB. Vector analysis of astigmatic changes after cataract surgery with implantation of a new toric multifocal intraocular lens. J Cataract Refract Surg. 2011;37(7):1217-29.

29. Alió JL, Plaza-Puche AB, Javaloy J, Ayala MJ. Comparison of the visual and intraocular optical performance of a refractive multifocal IOL with rotational asymmetry and an apodized diffractive multifocal IOL. J Refract Surg. 2012; 28(2):100-5.

30. Alió JL, Plaza-Puche AB, Javaloy J, Ayala MJ, Vega-Estrada A. Clinical and optical intraocular performance of rotationally asymmetric multifocal IOL plate-haptic design versus C-loop haptic design. J Refract Surg. 2013;29(4): 252-9.

31. Alió JL, Montalbán R, Peña-García P, Soria FA, Vega-Estrada A. Visual outcomes of a trifocal aspheric diffractive intraocular lens with microincision cataract surgery. J Refract Surg. 2013;29(11):756-61.

32. Alió JL, Plaza-Puche AB, Pinero DP, Javaloy J, Ayala MJ. Comparative analysis of the clinical outcomes with 2 multifocal intraocular lens models with rotational asymmetry. J Cataract Refract Surg. 2011;37(9):1605-14.

33. Alió JL, Plaza-Puche AB, Montalban R, Javaloy J. Visual outcomes with a single-optic accommodating intraocular lens and a low-addition-power rotational asymmetric multifocal intraocular lens. J Cataract Refract Surg. 2012;38(6):978-85.

34. Alfonso JF, Fernández-Vega Cueto L, Belda-Salmerón L, Montés-Micó R, Fernández-Vega L. Visual function after implantation of a diffractive aspheric trifocal intraocular lens. Eur J Ophthalmol. 2016;26(5):405-11.

35. Pomerance GN, Evans DW. Test-retest reliability of the CSV-1000 contrast test and its relationship to glaucoma therapy. Invest Ophthalmol Vis Sci. 1994:35(9):3357-61.

36. Alfonso JF, Puchades C, Fernandez-Vega L, Montés-Micó R, Valcárcel B, Ferrer-Blasco T. Visual acuity comparison of 2 models of bifocal aspheric intraocular lenses. J Cataract Refract Surg. 2009;35(4):672-6.

37. Ray WA, O'Day DM. Statistical analysis of multi-eye data in ophthalmic research. Invest Ophthalmol Vis Sci. 1985;26(8):1186-8.
Ready to submit your research? Choose BMC and benefit from:

- fast, convenient online submission

- thorough peer review by experienced researchers in your field

- rapid publication on acceptance

- support for research data, including large and complex data types

- gold Open Access which fosters wider collaboration and increased citations

- maximum visibility for your research: over $100 \mathrm{M}$ website views per year

At $\mathrm{BMC}$, research is always in progress.

Learn more biomedcentral.com/submissions 